\title{
Human papillomavirus infection and risk of breast cancer: a meta-analysis of case- control studies
}

\author{
Jong-Myon Bae* and Eun Hee Kim
}

\begin{abstract}
Background: Although systematic reviews (SR) report that human papillomavirus (HPV) increases the risk of breast cancer, there are still disputes regarding this association. In particular, it has been argued that the risk level differs depending on nationality, type of tissue, subtype of HPV, and publication year. Considering that the searching year of publication for the previous SRs was June 2013, a renewal meta-analysis needs to be conducted.

Methods: Using articles selected in the previous SRs, we compiled a list of references, cited articles, and related articles from the PubMed and Scopus databases. Of these, only publications with data from case-control studies on HPV DNA-positivity in tissues were chosen. Summary odds ratio (SOR) and $95 \%$ confidence interval (CI) were calculated through meta-analysis. Meta-regression analysis was performed for nationality, types of tissue, subtype of $H P V$, and publication year.

Results: Twenty-two case-control studies were selected, and the total number of individuals in the case and control group was 1897 and 948, respectively. According to the meta-analysis about the 22 publications, HPV infection increased the risk of breast cancer (SOR=4.02, $95 \% \mathrm{Cl}$ : 2.42-6.68; I-squared $=44.7 \%$ ). Statistical significance was not found in meta-regression performed on the four variables of nationality, type of tissue, subtype of HPV, and publication year which some researchers think sources of heterogeneity.

Conclusions: The results of the present study supported the argument that HPV infection increases the risk of breast cancer. Age-matched case-control studies are in need in the future.
\end{abstract}

Keyword: Breast neoplasms, Risk factor, Human Papillomavirus, Meta-analysis

\section{Background}

Breast cancer is a primary cancer that has one of the highest incidences in women worldwide [1,2]. Epidemiologically, breast cancer occurs at a younger age for Asians compared to individuals from western countries [3]. Similarly, the peak incidence of breast cancer among Korean women occurs around 45-49 years old, which is immediately before menopause, and decreases after this age, forming a single-peak curve [4]. Because the shape of this curve had been maintained for the last 20 years, it was reported that there was no cohort effect in ageperiod-cohort analysis [5]. Based on the epidemiological characteristics mentioned above, dense breast and

\footnotetext{
* Correspondence: jmbae@jejunu.ac.kr

Department of Preventive Medicine, Jeju National University School of Medicine, Jejudo, South Korea
}

(c) 2016 Bae and Kim. Open Access This article is distributed under the terms of the Creative Commons Attribution 4.0 International License (http://creativecommons.org/licenses/by/4.0/), which permits unrestricted use, distribution, and reproduction in any medium, provided you give appropriate credit to the original author(s) and the source, provide a link to the Creative Commons license, and indicate if changes were made. The Creative Commons Public Domain Dedication waiver (http://creativecommons.org/publicdomain/zero/1.0/) applies to the data made available in this article, unless otherwise stated.

human papillomavirus (HPV) were proposed as risk factors related to the development of breast cancer among Korean women [6,7].

In particular, the HPV infection theory is significant in the prevention of cancer because HPV vaccines are currently in use [8]. The association between HPV infection and breast cancer was first proposed in 1992 [9], and since then there was a report of HPV DNA being detected in breast cancer tissues of Korean women [10]. And three meta-analyses [11-13] reported that HPV DNA was detected in $23-30 \%$ of breast cancer tissues and the summary odds ratio (SOR) was 3.24-3.63 with statistical significance.

Nevertheless, there are still disputes about the association between HPV infection and the risk of breast cancer [14]. In particular, there is debate over the use of 
paraffin-embedded tissue (PET) to test for HPV DNApositivity because HPV DNA can be destroyed and become contaminated during the treatment procedure, meaning that PET will have more measurement errors than fresh frozen tissue (FFT) [15]. Although Li et al. [12] emphasized that HPV 33 was detected in all Asians, it was suggested that these regional differences can be attributed to differences in the testing method [15]. In addition, Zhou et al. [13] stressed that the risk of HPV infection was influenced by geographic region, HPV DNA source, PCR primer used, and publication year. However in the subgroup analysis, the confidence intervals of SOR overlapped with one another. Therefore, it is necessary to further examine whether these variables indeed cause heterogeneity. Furthermore, taking into account that the final search period of the 3 SRs was June 2013 [11], the meta-analysis needs to be adapted by additionally selecting literatures published up to September 2015. The objective of this study was to re-conduct meta-analysis with meta-regression on the relationship between HPV infection and the risk of breast cancer.

\section{Results and discussion}

Figure 1 depicts the process of selecting articles for the final analysis through a data search. Based on the 3 SRs to identify the association between HPV and the prevalence and odds ratio (OR) of breast cancer, a list was compiled containing 85 references and 8122 cited and related articles from PubMed and Scopus. We sequentially applied the selection criteria into the total $8207 \mathrm{pa}$ pers, and excluded (1) 8113 articles with a different hypothesis, (2) 21 articles that were expert reviews or systematic reviews, (3) 45 articles using case only studies, (4) 2 articles that were case-control studies without HPV DNA-positivity in both groups [16,17], and (5) 2 articles published using duplicate samples $[18,19]$. The older publication in 2005 by Tsai et al. [18] was excluded because the samples used were the same as a publication in 2007 [20] by the same group. In addition, the studies published in 2009 by Lawson et al. [19] and Hang et al. [21] used the same DNA specimens as each other; of these, Lawson et al. [19] was excluded based on the suitability of the hypothesis for our study.

Following the aforementioned exclusion process, 24 publications were selected for the meta-analysis $[10,14$, 20-41]. Table 1 summarizes the numbers of HPV DNApositive and HPV DNA-negative individuals in the case and control group in these 24 case-control studies, organized according to the nationality of the study subjects, types of DNA specimen, and 3 HPV subtypes. Of these studies, He et al. [28] and Fu et al. [40] used the same DNA specimens. Therefore, Fu et al. study published in 2015 [40] was used for the overall analysis, and He et al. study published in 2009 [28] was used only for analyzing the HPV 16 results. For similar reasons, data from Glenn et al. published in 2012 [33] was used for the

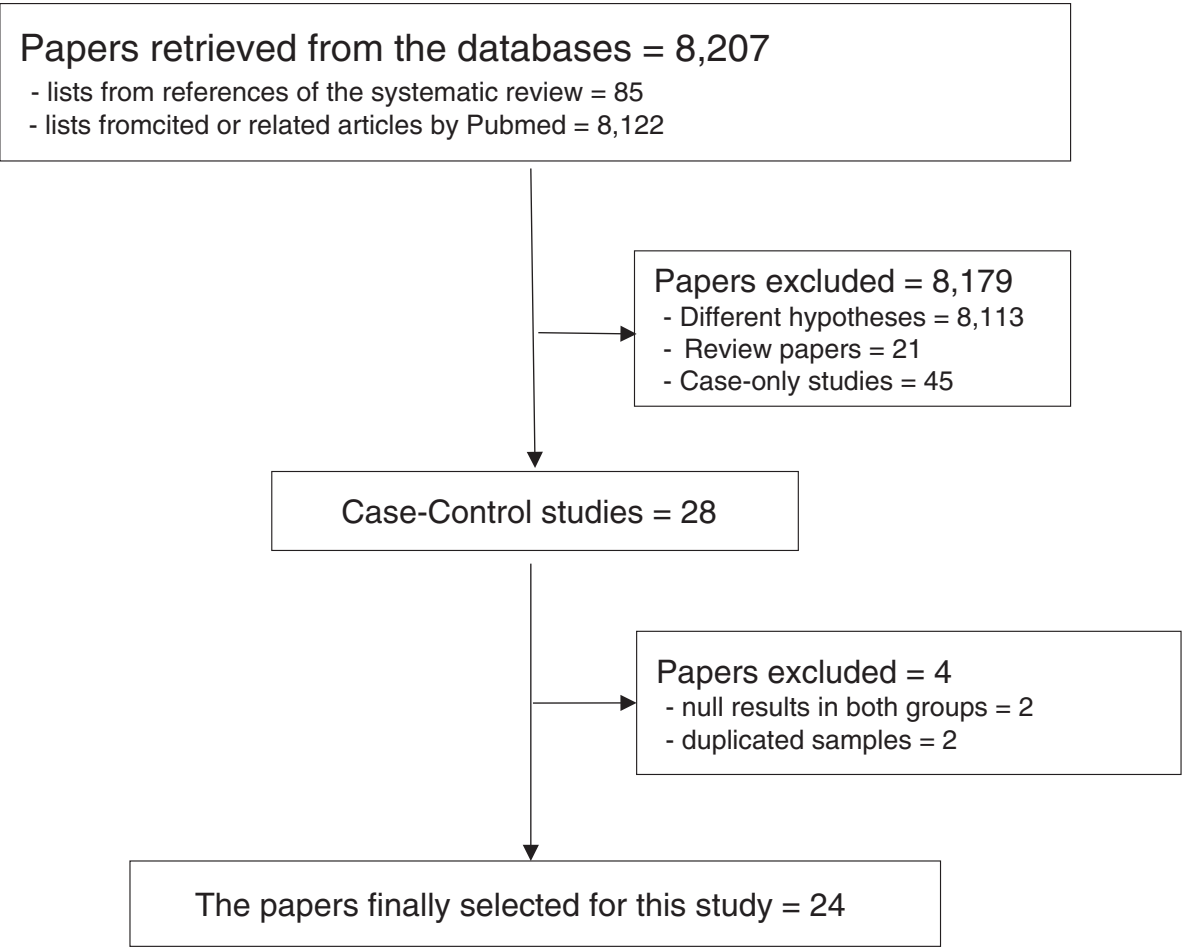

Fig. 1 Flow chart of article selection 
Table 1 Summary of the selected case-control studies by subtypes of human papillomavirus*

\begin{tabular}{|c|c|c|c|c|c|c|c|c|c|c|c|c|}
\hline \multirow[t]{2}{*}{ First author } & \multirow[t]{2}{*}{ Year of publication } & \multirow[t]{2}{*}{ Reference number } & \multirow[t]{2}{*}{ Nation } & \multirow{2}{*}{$\begin{array}{l}\text { Tissue } \\
\text { type }\end{array}$} & \multicolumn{2}{|c|}{ Any type } & \multicolumn{2}{|c|}{16 Subtype } & \multicolumn{2}{|c|}{18 Subtype } & \multicolumn{2}{|c|}{33 Subtype } \\
\hline & & & & & Case $(n / N)$ & Control $(\mathrm{n} / \mathrm{N})$ & Case $(n / N)$ & Control $(n / N)$ & Case $(n / N)$ & Control $(n / N)$ & Case $(n / N)$ & Control $(n / N)$ \\
\hline Yu & 1999 & 22 & China/Japan & PET & $18 / 52$ & $1 / 20$ & & & & & $18 / 52$ & $1 / 20$ \\
\hline Damin & 2004 & 23 & Brazil & PET & $25 / 101$ & $0 / 41$ & $14 / 101$ & $0 / 41$ & $10 / 101$ & $0 / 41$ & & \\
\hline de Villiers & 2005 & 24 & USA & PET & $25 / 29$ & $20 / 29$ & & & & & & \\
\hline Gumus & 2006 & 25 & Turkey & FFT & $37 / 50$ & $16 / 50$ & & & 20.37 & $9 / 16$ & $35 / 37$ & $14 / 16$ \\
\hline Choi & 2007 & 10 & Korea & PET & $8 / 123$ & $0 / 31$ & & & & & & \\
\hline Tsai & 2007 & 20 & China & FFT & $8 / 62$ & $2 / 32$ & & & & & & \\
\hline Khan & 2008 & 26 & Japan & PET & $26 / 124$ & $0 / 11$ & $24 / 124$ & $0 / 11$ & $3 / 124$ & $0 / 11$ & $1 / 124$ & $0 / 11$ \\
\hline de Leon & 2009 & 27 & Mexico & PET & $15 / 51$ & $0 / 43$ & $10 / 51$ & $0 / 43$ & $3 / 51$ & $0 / 43$ & & \\
\hline Mendiazabauiz & 2009 & 29 & Mexico & PET & $3 / 67$ & $0 / 40$ & & & & & & \\
\hline Herrera-Goepfert & 2011 & 41 & Mexico & PET & $6 / 60$ & $7 / 60$ & $6 / 60$ & $7 / 60$ & & & & \\
\hline Mou & 2011 & 30 & China & FFT & $4 / 62$ & $0 / 46$ & $3 / 62$ & $0 / 46$ & $1 / 62$ & $0 / 46$ & & \\
\hline Chang & 2012 & 31 & China & FFT & $0 / 48$ & $3 / 30$ & & & & & & \\
\hline Frega & 2012 & 32 & Italy & PET & $9 / 31$ & $0 / 12$ & & & & & & \\
\hline Glenn & 2012 & 33 & Australia & FFT & $25 / 50$ & $8 / 40$ & & & $25 / 50$ & $8 / 40$ & & \\
\hline Sigaroodi & 2012 & 34 & Iran & PET & $15 / 58$ & $1 / 41$ & $4 / 79$ & $0 / 51$ & $4 / 79$ & $0 / 51$ & & \\
\hline Liang & 2013 & 35 & China & FFT & $48 / 224$ & $6 / 37$ & & & & & & \\
\hline Ali & 2014 & 36 & Iraq & PET & $60 / 129$ & $3 / 44$ & $33 / 129$ & $0 / 44$ & $35 / 129$ & $1 / 44$ & $16 / 129$ & $1 / 44$ \\
\hline Ahangar-Oskouee & 2014 & 37 & Iran & PET & $22 / 65$ & $0 / 65$ & $1 / 65$ & $0 / 65$ & & & & \\
\hline Manzouri & 2014 & 38 & Iran & PET & $10 / 55$ & $7 / 51$ & $2 / 55$ & $0 / 51$ & $1 / 55$ & $0 / 51$ & $1 / 55$ & $0 / 51$ \\
\hline Peng & 2014 & 39 & China & FFT & $2 / 100$ & $0 / 50$ & & & $2 / 100$ & $0 / 50$ & & \\
\hline $\mathrm{Fu}$ & 2015 & 40 & China & PET & $25 / 169$ & $1 / 83$ & & & & & & \\
\hline $\mathrm{Li}$ & 2015 & 14 & China & PET & $3 / 187$ & 0/92 & & & & & & \\
\hline $\mathrm{He}$ & 2009 & 28 & China & FFT & & & $24 / 40$ & $1 / 20$ & & & & \\
\hline Heng & 2009 & 21 & Australia & PET & & & $1 / 26$ & $0 / 17$ & & & & \\
\hline
\end{tabular}

*(n/N) number of positive on the tested samples, FFT fresh frozen tissue, PET paraffin-embedded tissue 
overall and HPV 18 analyses, while the data from Heng et al. published in 2009 [21] was used for analyzing the HPV 16 results. Therefore, in the 22 publications of case-control studies excluding the 2 articles that used DNA specimens from the same hospital [21,28], there were 1897 and 948 individuals in the case and control group, respectively. When categorized by region, there were 10 articles in far-east Asia, 5 articles in middle-east Asia, and 7 articles in other regions. By specimen type, there were 15 articles using PET and 7 articles using FFT. When the data was organized by HPV subtype, there were 11 articles on HPV 16, 10 articles on HPV 18, and 5 articles on HPV 33.

Regardless of HPV subtype, the risk of breast cancer was 4.02-fold higher ( $95 \%$ CI: 2.42-6.68: I-squared $=44.7 \%$ ) for HPV DNA-positive individuals (Fig. 2). The Egger test was used to determine publication bias, and the bias coefficient was 0.91 which was not statistically significant $(p=0.165)$ (Fig. 3$)$.
Table 2 summarizes the results of subgroup analysis by HPV subtype, region, and type of DNA specimen. Results by region showed that risk of breast cancer for HPV DNA-positive individuals was 7.04-fold higher in middle-east Asia (95 \% CI: 2.43-20.42), 4.23-fold higher in America regions (95\% CI: 1.06-16.84), and 2.60-fold higher in far-east Asia (95 \% CI: 1.25-5.38). By specimen type, the risk was 5.60 -fold higher for PET (95\% CI: 2.79-11.25) and 2.61-fold higher for FFT (95 \% CI: 1.225.61). Although there were differences in SOR by region, specimen type and publication periods, all risks were statistically significant. However, the CIs of SORs all overlapped.

When we examined the results by HPV subtype, the risk of breast cancer was, in descending order, 5.67-fold higher for HPV 16 (95 \% CI: 2.21-14.52), 3.64-fold higher for HPV 33 (95\% CI: 1.26-10.48), and 2.97-fold higher for HPV 18 (95\% CI: 1.64-5.38), and all risks were statistically significant. Again, the CIs of SORs were overlapping for 3 subtypes.

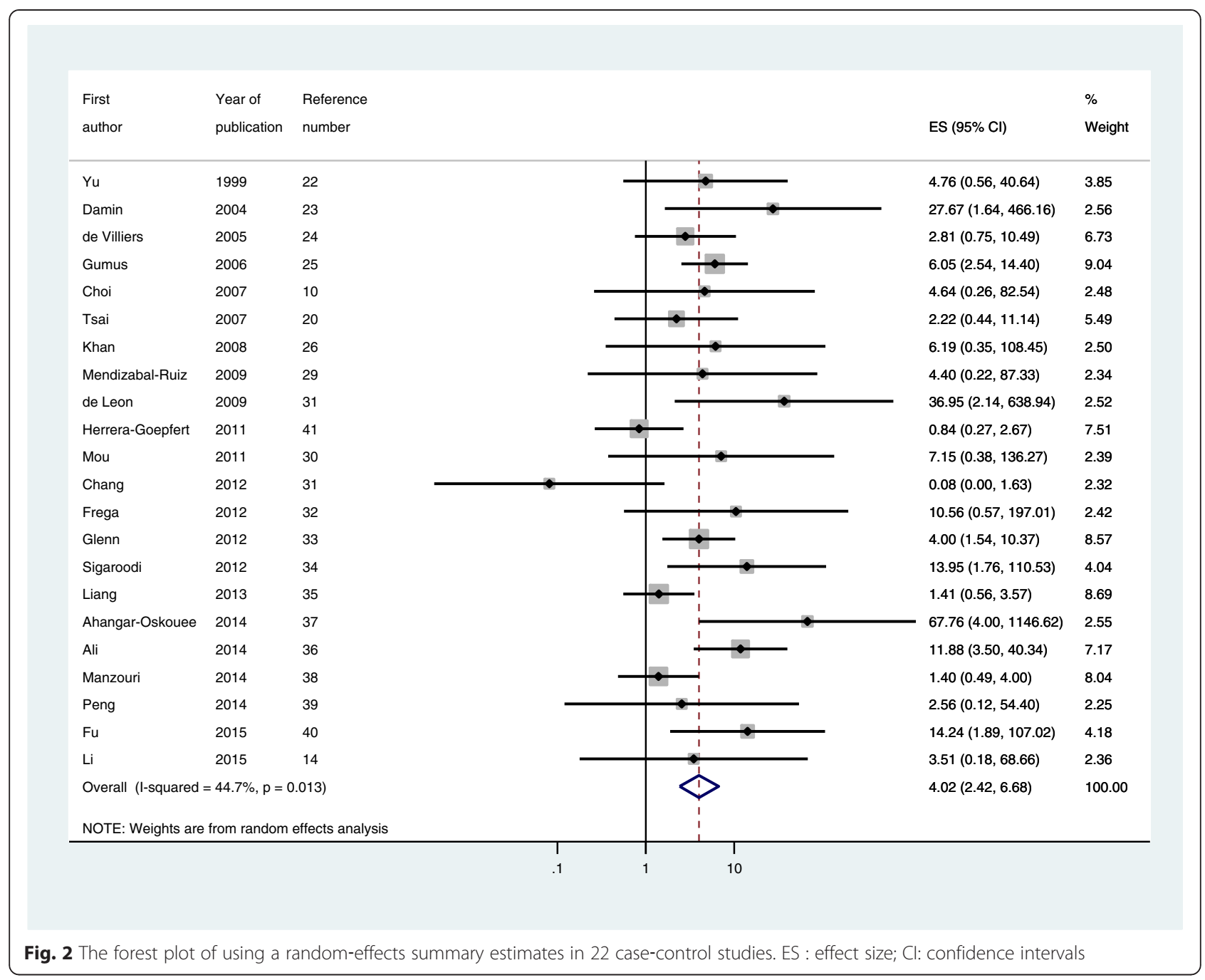




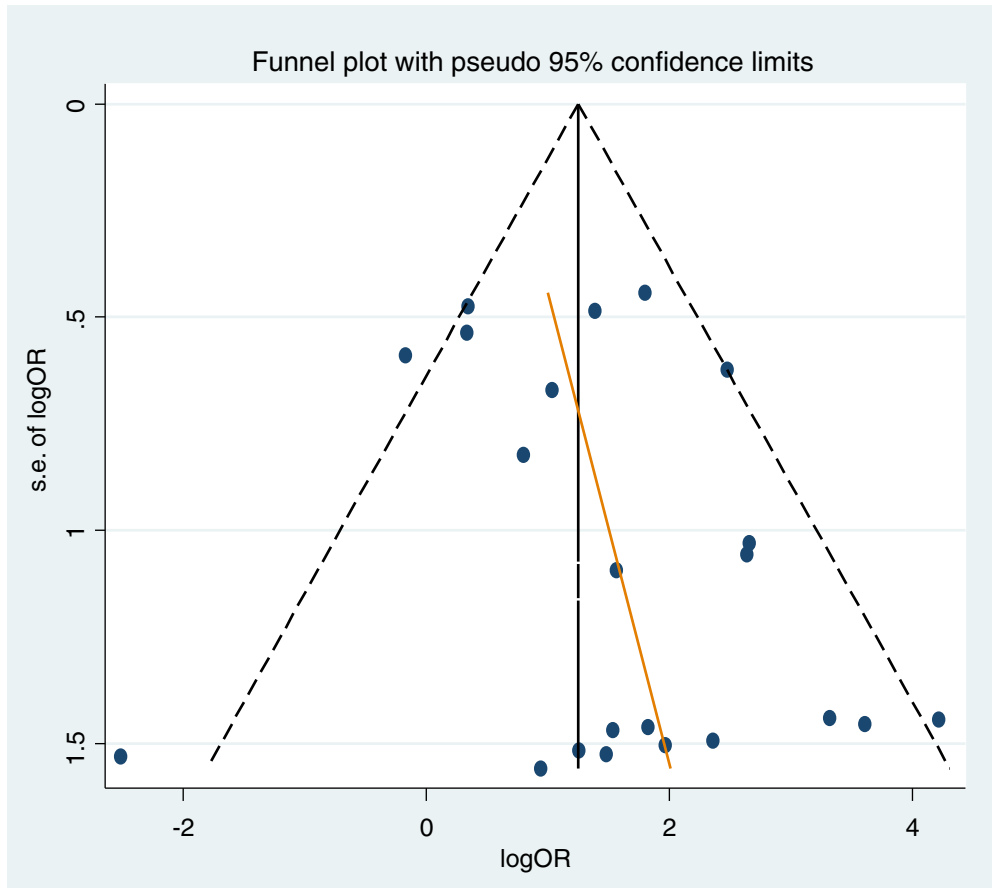

Fig. 3 The funnel plot of using a mixed-effects summary estimates in 22 articles ( $P$-value of Egger test $=0.165)$. LogOR: log odds ratio; s.e.of logOR: standard error of log odds ratio

The meta-regression analysis was performed on 26 datasets created around three subtypes, with nationality, types of tissue, subtype, and publication year as the variables. None of the variables showed statistical significance (not shown).

In order to satisfy the criteria to prove that a specific virus causes cancer [42], case-control studies must be performed instead of case only studies [43]. However, tumor-based case-control studies are susceptible to measurement errors $[44,45]$, and thus, systematic reviews are needed to overcome this shortcoming.

According to the meta-analysis for results from 22 case-control studies, the risk of breast cancer due to HPV infection was 4.02-fold higher. Even when the results were analyzed by categorizing into four regions, two types of DNA specimen and two publication periods, the risk of breast cancer due to HPV was statistically significant. The findings provide supporting evidence for the HPV infection as a risk factor of breast cancer. Additionally, the CIs of SOR calculated in the subgroup analysis were overlapping with one another, and the results from meta-regression analysis showed that none of the 4 variables caused heterogeneity. These findings support the validity of the SOR calculated in the meta-analysis.

The estimated SOR in this study was similar to previous meta-analysis results (Table 3 ). However, our metaanalysis retrieved results from 22 case-control studies, and therefore, has a narrower confidence interval because we were able to retrieve publications that were not selected through electronic search. The list of 22 publications gathered in this manner will be important for renewal meta-analyses in the future.

Early study results were confusing, due to inappropriate experimental design, small sample sizes, and unstandardized HPV DNA detection methods [11,14,15]. However, Li et al. [12] commented that consistent study results have been reported since 2006. Therefore, we tried to conduct a subgroup analysis by dividing into before and after 2006, but because only 3 of the 21 publications were before 2006, we performed analysis with 2010 as the cut point. In terms of selecting region variables, 9 out of 16 studies selected in Zhou et al. [13] had Asian subjects, whereas in this study it was 15 out of 22 studies that had Asian subjects. Thus, in the study, an analysis was done after the 15 studies were separated into 10 far-east and 5 middle-east Asia studies. Also, Zhou et al. [13] reported the difference for each PCR primer even if the CIs of SORs overlapped. In this study, we used the subtype variable, in lieu of the variable of PCR primer used. That is, we created 26 sets of database after dividing HPV into 3 subtypes (16, 18, and 33) and examined SOR by subtype. Not only the results showed that the CIs of SOR calculated by subtype overlapped, but also we confirmed no statistical significance with a meta-regression analysis. 
Table 2 Subgroup analyses by subtypes of human papillomavirus

\begin{tabular}{|c|c|c|c|c|c|}
\hline Types & Sub-group & & Numbers & I-squared (\%) & SOR with $95 \% \mathrm{Cl}$ by REM \\
\hline \multirow[t]{9}{*}{ Any } & & & 22 & 44.7 & $4.02[2.42-6.68]$ \\
\hline & Nationality of subjects & Far-East & 10 & 16.4 & $2.60[1.25-5.38]$ \\
\hline & & Middle-East & 5 & 66.4 & $7.04[2.43-20.42]$ \\
\hline & & America & 5 & 59.2 & $4.23[1.06-16.84]$ \\
\hline & & Europe \& Oceania & 2 & 0.0 & $4.39[1.77-10.86]$ \\
\hline & Specimen types & PET & 15 & 45.4 & $5.60[2.79-11.25]$ \\
\hline & & FFT & 7 & 47.5 & $2.61[1.22-5.61]$ \\
\hline & Year of publication & -2010 & 9 & 0.0 & 5.10 [2.89-8.99] \\
\hline & & $2011-$ & 13 & 60.1 & $3.55[1.68-7.50]$ \\
\hline \multirow[t]{8}{*}{16} & & & 11 & 32.5 & $5.67[2.21-14.52]$ \\
\hline & Nationality of subjects & Far-East & 3 & 0.0 & $12.37[2.83-54.15]$ \\
\hline & & Middle-East & 4 & 0.0 & 7.87 [1.76-35.23] \\
\hline & & America & 4 & 54.3 & $3.58[0.61-21.03]$ \\
\hline & Specimen types & PET & 9 & 25.9 & $4.25[1.57,11.54]$ \\
\hline & & FFT & 2 & 0.0 & 16.47 [2.94-92.18] \\
\hline & Year of publication & -2010 & 5 & 0.0 & $12.47[3.73-41.71]$ \\
\hline & & $2011-$ & 6 & 30.1 & $3.25[0.97-10.87]$ \\
\hline \multirow[t]{8}{*}{18} & & & 10 & 0.0 & $2.97[1.64-5.38]$ \\
\hline & Nationality of subjects & Far-East & 3 & 0.0 & $1.54[0.26-9.20]$ \\
\hline & & Middle-East & 4 & 52.5 & $3.37[0.70-16.22]$ \\
\hline & & America & 3 & 0.0 & 4.50 [1.89-10.68] \\
\hline & Specimen types & PET & 7 & 28.0 & 3.13 [1.09-9.03] \\
\hline & & FFT & 3 & 0.0 & $3.70[1.54-8.88]$ \\
\hline & Year of publication & -2010 & 4 & 12.4 & $1.59[0.51-4.96]$ \\
\hline & & $2011-$ & 6 & 0.0 & $4.62[2.17-9.81]$ \\
\hline \multirow[t]{7}{*}{33} & & & 5 & 0.0 & $3.64[1.26-10.48]$ \\
\hline & Nationality of subjects & Far-East & 2 & 69.6 & $2.10[0.06-68.51]$ \\
\hline & & Middle-East & 3 & 0.0 & 3.70 [0.98-13.90] \\
\hline & Specimen types & PET & 5 & 0.0 & $3.64[1.26-10.48]$ \\
\hline & & FFT & - & - & - \\
\hline & Year of publication & -2010 & 3 & 40.4 & $2.64[0.44-15.76]$ \\
\hline & & $2011-$ & 2 & 0.0 & $4.88[0.87-27.56]$ \\
\hline
\end{tabular}

Clconfidence intervals, FFT fresh frozen tissue, PET paraffin-embedded tissue, REM random effect model

Table 3 Comparison of three meta-analyses for HPV infection and breast cancer risk

\begin{tabular}{llllll}
\hline First author [reference number] & Searching Periods & Selected articles & Total Cases & Total Controls & SOR (95 \% Cl) \\
\hline Li [12] & - May 2010 & 10 & 447 & 275 & $3.63(1.42-9.27)$ \\
Simoes [11] & - Jan 2011 & 9 & 448 & 279 & $5.9(3.23-10.67)$ \\
Zhou [13] & - Jun 2013 & 16 & n.d. & n.d. & $3.24(1.59-6.57)$ \\
This study & - Sep 2015 & 22 & 1897 & 948 & $4.02(2.42-6.68)$
\end{tabular}


Regarding the link between the Epstein-Barr virus infection and breast cancer, it has been argued that different kinds of control tissue cause heterogeneity [46]. Of the 22 selected studies, we found that only 2 studies used adjacent normal cells from the cancer tissue $[24,41]$, and the remaining 20 studies used normal breast cells of non-cancer tissues. Therefore, an additional analysis by type of control tissue was not performed.

It has been proposed that not only HPV but also herpesvirus, polyomavirus, and beta retrovirus increase the risk of breast cancer [47]. Proving these theories related to viral infection is of great significance because it opens up the possibility of using antiviral drugs to treat breast cancer and vaccines to prevent breast cancer $[8,48]$.

\section{Conclusions}

In conclusion, this meta-analysis supports the hypothesis that HPV infection is a risk factor for breast cancer. In near future, it is anticipated that nested case-control studies will be actively performed, along with agematched case-control studies.

\section{Methods}

\section{Search and selection of related articles}

Since we were using 3 previously published systematic reviews [11-13], we used the hand search method rather than the electronic search method [49,50]. Publications were found by searching the references of articles selected in these 3 systematic reviews on the preferential basis. And then lists of "cited articles" and "similar (related) articles" provided by the PubMed (www.ncbi.nlm.nih.gov/ pubmed) and Scopus (www.elsevier.com/solutions/scopus) databases for each article were also considered for inclusion. This searching strategy assumes that studies conducted with the 'same research hypothesis' have a high possibility of being cited in related articles and that they will have similar findings [51].

The final selection criteria were case-control studies that detected HPV DNA in the tissue. Based on the titles and abstracts for the papers in the compiled list, the following 5 exclusion criteria were applied sequentially. (1) Articles with different hypothesis, (2) expert reviews or systematic reviews, (3) case only studies, (4) case-control studies without HPV DNA-positivity in both groups, and (5) articles published by using the same DNA samples as another study. The remaining case-control studies after applying the 5 aforementioned criteria were selected as publications for the final analysis.

\section{Statistical analysis}

Two researchers applied the exclusion criteria for each publication and retrieved HPV-related data-the number of HPV DNA-positive and HPV DNA-negative individuals in the case and control group, nationality of study subjects, types of DNA specimen, types of HPV subtypes, and publication period. Using the obtained number of HPV DNA-positive and HPV DNA-negative individuals in the case and control group, OR and $95 \%$ CI were calculated for each article. Based on the prevalence of HPV subtypes reported by the Zhou et al. [13], data on high-risk type-specific HPV 16, 18, and 33 were organized separately. Based on the nationality of study subjects, groups were categorized into far-east Asia (Korea, China, and Japan), middle-east Asia (Turkey, Iran, and Iraq), America, and Europe \& Oceania regions. Specimen types were classified into PET and FFT groups. Publication year was divided into 2 groups with 2010 as the cut point.

The presence of heterogeneity in meta-analysis was assessed using the I-squared value (\%). The summary odds ratio (SOR) for a random effect model and its $95 \%$ $\mathrm{CI}$ were calculated first because if the I-squared value is $0.0 \%$, using either a random effect model or a fixed effect model will result in the same value. To determine the publication bias, Egger's test for small-study effects was conducted [52]. Additionally, a subgroup analysis and a meta-regression analysis were conducted using the 4 potential variables thought to cause heterogeneity in risks-geographic region, HPV DNA source, publication year, and subtype of HPV. P-value of less than $5 \%$ was considered statistically significant, and STATA version 14 (www.stata.com) statistics program was used.

\section{Competing interests}

The authors have no conflicts of interest with the material presented in this paper.

\section{Authors' contributions}

JB designed, appraised, and wrote the systematic review; EK searched and appraised the related articles; Both authors read and approve the manuscript.

\section{Acknowledgements}

This study was supported by a grant funded in 2013 by the Korean

Foundation for Cancer Research, Korea (no. 2013-2).

Received: 16 November 2015 Accepted: 1 March 2016

Published online: 14 March 2016

\section{References}

1. Tfayli A, Temraz S, Abou Mrad R, Shamseddine A. Breast cancer in low- and middle-income countries: an emerging and challenging epidemic. J Oncol. 2010;2010:490631.

2. Siegel R, Ma J, Zou Z, Jemal A. Cancer statistics, 2014. CA Cancer J Clin. 2014;64:9-29.

3. Huang CS, Lin CH, Lu YS, Shen CY. Unique features of breast cancer in Asian women-breast cancer in Taiwan as an example. J Steroid Biochem Mol Biol. 2010;118:300-3.

4. Shin HR, Joubert C, Boniol M, Hery C, Ahn SH, Won YJ, et al. Recent trends and patterns in breast cancer incidence among Eastern and Southeastern Asian women. Cancer Causes Control. 2010;21:1777-85.

5. Cho HJ, Joo WH, Kim YN, Bae JM, Nam CM. Cohort effects of female breast cancer incidence in Korea. J Health Inform Stat. 2014;39:32-43 (Korean).

6. Park IH, Ko K, Joo J, Park B, Jung SY, Lee S, et al. High volumetric breast density predicts risk for breast cancer in postmenopausal, but not premenopausal, Korean women. Ann Surg Oncol. 2014;21:4124-32. 
7. Bae JM. Two hypotheses of dense breasts and viral infection for explaining incidence of breast cancer by age group in Korean women. Epidemiol Health. 2014;36:e2014020.

8. Lowy DR, Schiller JT. Reducing HPV-associated cancer globally. Cancer Prev Res. 2012;5:18-23

9. Di Lonardo A, Venuti A, Marcante ML. Human papillomavirus in breast cancer. Breast Cancer Res Treat. 1992;21:95-100.

10. Choi YL, Cho EY, Kim JH, Nam SJ, Oh YL, Song SY, et al. Detection of human papillomavirus DNA by DNA chip in breast carcinomas of Korean women. Tumour Biol. 2007;28:327-32.

11. Simões PW, Medeiros LR, Simões Pires PD, Edelweiss MI, Rosa DD, Silva FR et al. Prevalence of human papillomavirus in breast cancer: a systematic review. Int J Gynecol Cancer. 2012;22:343-7.

12. Li N, Bi X, Zhang Y, Zhao P, Zheng T, Dai M. Human papillomavirus infection and sporadic breast carcinoma risk: a meta-analysis. Breast Cancer Res Treat. 2011;126:515-20

13. Zhou Y, Li J, Ji Y, Ren M, Pang B, Chu M, et al. Inconclusive role of human papillomavirus infection in breast cancer. Infect Agent Cancer. 2015;10:36.

14. Li J, Ding J, Zhai K. Detection of Human Papillomavirus DNA in Patients with Breast Tumor in China. PLoS One. 2015;10:e0136050.

15. Wang T, Chang P, Wang L, Yao Q, Guo W, Chen J, et al. The role of human papillomavirus infection in breast cancer. Med Oncol. 2012;29:48-55.

16. Bratthauer GL, Tavassoli FA, O'Leary TJ. Etiology of breast carcinoma: no apparent role for papillomavirus types 6/11/16/18. Pathol Res Pract. 1992; 188:384-6.

17. Vernet-Tomas M, Mena M, Alemany L, Bravo I, De Sanjosé S, Nicolau P, et al. Human papillomavirus and breast cancer: no evidence of association in a Spanish set of cases. Anticancer Res. 2015;35:851-6.

18. Tsai JH, Tsai CH, Cheng MH, Lin SJ, Xu FL, Yang CC. Association of vira factors with non-familial breast cancer in Taiwan by comparison with noncancerous, fibroadenoma, and thyroid tumor tissues. J Med Virol. 2005;75:276-81.

19. Lawson JS, Glenn WK, Heng B, Ye Y, Tran B, Lutze-Mann L, et al. Koilocytes indicate a role for human papilloma virus in breast cancer. Br J Cancer. 2009:101:1351-6.

20. Tsai JH, Hsu CS, Tsai CH, Su JM, Liu YT, Cheng MH, et al. Relationship between viral factors, axillary lymph node status and survival in breast cancer. J Cancer Res Clin Oncol. 2007;133:13-21.

21. Heng B, Glenn WK, Ye Y, Tran B, Delprado W, Lutze-Mann L, et al. Human papilloma virus is associated with breast cancer. Br J Cancer. 2009;101:1345-50.

22. Yu Y, Morimoto T, Sasa M, Okazaki K, Harada Y, Fujiwara T, et al. HPV33 DNA in premalignant and malignant breast lesions in Chinese and Japanese populations. Anticancer Res. 1999;19:5057-61.

23. Damin AP, Karam R, Zettler CG, Caleffi M, Alexandre CO. Evidence for an association of human papillomavirus and breast carcinomas. Breast Cancer Res Treat. 2004:84:131-7.

24. de Villiers EM, Sandstrom RE, zur Hausen H, Buck CE. Presence of papillomavirus sequences in condylomatous lesions of the mamillae and in invasive carcinoma of the breast. Breast Cancer Res. 2005;7:R1-11.

25. Gumus M, Yumuk PF, Salepci T, Aliustaoglu M, Dane F, Ekenel M, et al. HPV DNA frequency and subset analysis in human breast cancer patients' normal and tumoral tissue samples. J Exp Clin Cancer Res. 2006:25:515-21.

26. Khan NA, Castillo A, Koriyama C, Kijima Y, Umekita Y, Ohi Y, et al. Human papillomavirus detected in female breast carcinomas in Japan. Br J Cancer. 2008;99:408-14.

27. de León DC, Montiel DP, Nemcova J, Mykyskova I, Turcios E, Villavicencio V, et al. Human papillomavirus (HPV) in breast tumors: prevalence in a group of Mexican patients. BMC Cancer. 2009;9:26.

28. He Q, Zhang SQ, Chu YL, Jia XL, Wang XL. The correlations between HPV16 infection and expressions of c-erbB-2 and bcl-2 in breast carcinoma. Mol Biol Rep. 2009;36:807-12

29. Mendizabal-Ruiz AP, Morales JA, Ramírez-Jirano LJ, Padilla-Rosas M, MoránMoguel MC, Montoya-Fuentes H. Low frequency of human papillomavirus DNA in breast cancer tissue. Breast Cancer Res Treat. 2009;114:189-94.

30. Mou X, Chen L, Liu F, Shen Y, Wang H, Li Y, et al. Low prevalence of human papillomavirus (HPV) in Chinese patients with breast cancer. J Int Med Res. 2011;39:1636-44

31. Chang P, Wang T, Yao Q, Lv Y, Zhang J, Guo W, et al. Absence of human papillomavirus in patients with breast cancer in north-west China. Med Oncol. 2012;29:521-5.
32. Frega A, Lorenzon L, Bononi M, De Cesare A, Ciardi A, Lombardi D, et al. Evaluation of E6 and E7 mRNA expression in HPV DNA positive breast cancer. Eur J Gynaecol Oncol. 2012;33:164-7.

33. Glenn WK, Heng B, Delprado W, lacopetta B, Whitaker NJ, Lawson JS. EpsteinBarr virus, human papillomavirus and mouse mammary tumour virus as multiple viruses in breast cancer. PLoS One. 2012;7:e48788.

34. Sigaroodi A, Nadji SA, Naghshvar F, Nategh R, Emami H, Velayati AA. Human papillomavirus is associated with breast cancer in the north part of Iran. ScientificWorldJournal. 2012;2012:837191.

35. Liang W, Wang J, Wang C, LV Y, Gao H, Zhang K, et al. Detection of high-risk human papillomaviruses in fresh breast cancer samples using the hybrid capture 2 assay. J Med Virol. 2013;85:2087-92.

36. Ali SH, Al-Alwan NA, Al-Alwany SH. Detection and genotyping of human papillomavirus in breast cancer tissues from Iraqi patients. East Mediterr Health J. 2014;20:372-7.

37. Ahangar-Oskouee M, Shahmahmoodi S, Jalilvand S, Mahmoodi M, Ziaee AA, Esmaeili HA, et al. No detection of 'high-risk' human papillomaviruses in a group of Iranian women with breast cancer. Asian Pac J Cancer Prev. 2014;15:4061-5.

38. Manzouri L, Salehi R, Shariatpanahi S, Rezaie P. Prevalence of human papilloma virus among women with breast cancer since 2005-2009 in Isfahan. Adv Biomed Res. 2014:3:75.

39. Peng J, Wang T, Zhu H, Guo J, Li K, Yao Q, et al. Multiplex PCR/mass spectrometry screening of biological carcinogenic agents in human mammary tumors. J Clin Virol. 2014;61:255-9.

40. Fu L, Wang D, Shah W, Wang Y, Zhang G, He J. Association of human papillomavirus type 58 with breast cancer in Shaanxi province of China. J Med Virol. 2015;87:1034-40.

41. Herrera-Goepfert R, Kahn NA, Koriyama C, Akiba S, Perez-Sanchez VM. High-risk human papillomavirus in mammary gland carcinomas and non-neoplastic tissues of Mexican women: No evidence supporting a cause and effect relationship. Breast. 2011;20:184-9.

42. Vonka V. Causality in medicine: the case of tumours and viruses. Philos Trans R Soc Lond B Biol Sci. 2000;355:1831-41.

43. Liang $\mathbf{W}$, Tian $\mathrm{H}$. Hypothetic association between human papillomavirus infection and breast carcinoma. Med Hypotheses. 2008;70:305-7.

44. Engels EA, Wacholder S, Katki HA, Chaturvedi AK. Tumor-based case-control studies of infection and cancer: muddling the when and where of molecular epidemiology. Cancer Epidemiol Biomarkers Prev. 2014:23:1959-64.

45. Joshi D, Buehring GC. Are viruses associated with human breast cancer? Scrutinizing the molecular evidence. Breast Cancer Res Treat. 2012;135:1-15.

46. Chen $\mathrm{XZ}$, Chen $\mathrm{H}$, Castro FA, Hu JK, Brenner H. Epstein-Barr virus infection and gastric cancer. A systematic review. Medicine. 2015;94:e792.

47. Alibek K, Kakpenova A, Mussabekova A, Sypabekova M, Karatayeva N. Role of viruses in the development of breast cancer. Infect Agent Cancer. 2013;8:32.

48. Alibek K, Bekmurzayeva A, Mussabekova A, Sultankulov B. Using antimicrobial adjuvant therapy in cancer treatment: a review. Infect Agent Cancer. 2012;7:33.

49. Bae JM. Narrative reviews. Epidemiol Health. 2014:36:e2014018.

50. Bae JM. Human papillomavirus 16 infection as a potential risk factor for prostate cancer: an adaptive meta-analysis. Epidemiol Health. 2015;37:e2015005

51. Bae JM, Kim EH. Useful options of searching databases in conducting adaptive meta-analysis for updating systematic review. J Prev Med Public Health. 2016 (in press).

52. Harbord RM, Egger M, Sterne JA. A modified test for small-study effects in meta-analyses of controlled trials with binary endpoints. Stat Med. 2006:25:3443-57. 